\title{
TRAJETÓRIAS ESPAÇO-TEMPORAIS E DES-RETERRITORIALIZAÇÃO SUBALTERNA: A CAMPANHA GAÚCHA REVISITADA
}

\author{
Anderson Luiz Machado dos Santos* \\ Universidade Estadual de Maringá
}

Resumo: Este artigo objetiva contribuir para a interpretação da diversidade territorial da região da Campanha Gaúcha, sob a perspectiva de sujeitos subalternizados em seus territórios. Neste intento, dois componentes conceituais são acionados: a concepção de trajetórias espaço-temporais e a leitura dos processos de desreterritorialização subalterna. Assim, no primeiro momento da narrativa, apresentam-se as concepções nas quais o espaço-tempo se constitui em uma categoria-chave e o território em um conceito para a ciência geográfica. Diante da questão, delineia-se uma abordagem em que as trajetórias espaço-temporais podem ser vistas enquanto uma ponte conceitual para adentrar-se aos processos de des-reterritorialização que conformam um território. Já, no segundo momento, busca-se desdobrar como esses componentes se colocam como ferramentas para a revisitar a Campanha Gaúcha, desde sujeitos subalternizados, em espaços-tempos denominados de rincões - uma expressão nativa, que pode ser compreendida como um território em construção, sob a perspectiva de seus sujeitos subalternos.

Palavras-chave: Campanha Gaúcha, Trajetórias, Espaço-tempo, Des-reterritorialização, Subalternos.

\section{SPACE-TIME TRAJECTORIES AND SUBALTERN DE-RETERRITORIALIZATION: THE CAMPANHA GAÚCHA REVISITED}

Abstract: This work aims at contributing to the interpretation of the territorial diversity of the region of Campanha Gaúcha from the perspective of subalternized subjects in their territories. With this objective, two conceptual components arise: the formulation of space-time trajectories and the interpretation of the subaltern de-reterritorialization processes. Thus, the narrative presents, at first, the conceptions in which the space-time is a key-category and the territory is a concept for the geographic science. Given the question, it outlines an approach in which the space-time trajectories can be seem as a conceptual bridge in order to look inside the de-reterritorialization processes that constitute a territory. In a second moment, it seeks to unfold how these components are used as tools to revisit the Campanha Gaúcha from the subalternized subjects, in space-times referred as rincões - a native expression, which can be understood as a territory under construction, from the perspective of their subaltern subjects.

Keywords: Campanha Gaúcha, Trajectories, Space-time, De-reterritorialization, Subalterns.

\section{TRAYECTORIAS ESPACIO-TEMPORALES Y DES-RETERRITORIALIZACIÓN SUBALTERNA: LA CAMPAÑA GAUCHA REVISITADA}

Resumen: Este artículo tiene como objetivo contribuir a la interpretación de la diversidad territorial de la región de la Campaña Gaucha, bajo la perspectiva de sujetos subalternizados en sus territorios. Para lo cual, dos componentes conceptuales son adicionados: la concepción de las trayectorias espacio-temporales y la lectura de procesos de des-reterritorialización subalterna. Así, en el primer momento del texto, presentamos las concepciones en las que el espacio-tiempo se constituye como una categoría clave y el territorio en un concepto perteneciente a la ciencia geográfica. En efecto, delante de la cuestión central, se delinea un enfoque en el que las trayectorias espacio-temporales pueden verse como un puente conceptual para entrar en los procesos de des-reterritorialización que forman un territorio. En el segundo momento, buscamos desarrollar cómo estos componentes se colocan como herramientas para revisitar la Campaña Gaucha, a partir de los sujetos subalternizados, ubicados en espacio-tiempo llamados de rincón - una expresión nativa, que puede ser entendida como un territorio en construcción, desde la perspectiva de sus sujetos subalternizados.

Palabras clave: Campaña Gaucha, Trayectorias, Espacio-Tiempo, Des-reterritorialización, Subalternos. 
Introdução

Este artigo compreende a região da Campanha Gaúcha enquanto um espaço-tempo des-articulado no Brasil Meridional, que apresenta singularidades e diferenciações. Esse espaço-tempo notabilizou-se no contexto meridional pela formação do latifúndio pastoril (grandes estâncias), cujas forças materiais e representações ofereceram a todos os habitantes do Rio Grande do Sul uma profunda ressignificação de sua própria cultura, forjando uma identidade regional, desde o espaço latifundiário, conforme evidenciou Haesbaert (1988). Por outro lado, com a situação de crise da economia estancieira, novos processos emergiram neste limiar de século $X X I$, sobretudo com o avanço do agronegócio, em paradoxo com a luta pela terra organizada por movimentos sociais, como demonstraram os trabalhos de Heidrich (2000) e Chelotti (2009), respectivamente.

Entretanto, para além de um regime territorial ${ }^{1}$ de hegemonia e dominação que se impôs na Campanha Gaúcha e dos conflitos abertos, há uma multiplicidade de práticas e saberes presentes noutras territorialidades que se situam para além do espectro visível desse regime. Não obstante, para se aproximar de suas existências, é fundamental tomar o espaço-tempo em questão, de outra forma. Do ponto de vista epistemológico, considera-se fundamental, situá-lo enquanto esfera de encontro das multiplicidades, em caráter de permanente construção segundo Massey (2008), bem como compreendêlo na condição de categoria da prática como propõe Haesbaert (2010, 2014), com base em Bourdieu (2005), ou seja, através das noções do senso comum, presente nas práticas cotidianas do discurso ordinário.

Nessa perspectiva, se valorizam os termos nativos oriundos dos saberes dos múltiplos sujeitos que constroem o espaço regional. Conforme Souza (2013), na interface entre geografia e antropologia, tais termos ou categorias, podem transitar, para o pesquisador, da condição de categorias nativas para aquelas de categorias de análise da realidade. Não obstante, essa perspectiva também implica no compromisso com as existências dos sujeitos subalternizados, desde um posicionamento que visa in-corporar a produção de

1 Foucault (1995[1982]) explica que um regime de saber-poder é o modo pelo qual o saber circula e funciona suas relações, com o poder. Assim, identificou em seus estudos a formação de um regime de verdade sob a égide de um discurso científico, que sujeitou diversos saberes, considerados desqualificados. Desta forma, um regime, pode ser interpretado em termos de relações de sujeição e subalternização existentes no espaço-tempo. Em termos territoriais, esse regime de saber-poder pode se aproximar da caracterização feita por Raffestin (1993 [1980]), como o desejo de poder em uma malha territorial. "Quando a malha é "desejada" por um poder, este se esforça por escolher o sistema que melhor corresponda ao seu projeto, pronto a transformar a existência daqueles que a ele estão submetidos, a menos que estes recuperem o seu poder para se oporem ao outro poder" (RAFFESTIN, 1993 [1980] p.170 [grifos do autor]) saberes que foi des-incorporada pelo projeto moderno de razão e de conhecimento (MIGNOLO, 2005).

Assim, este artigo objetiva contribuir para a interpretação de elementos da região da Campanha Gaúcha, do ponto de vista da diversidade de sujeitos inscritos em seu regime territorial hegemônicodominante, ainda que subalternizados. Neste intento, dois componentes conceituais são utilizados como ferramentas para resgatar uma pesquisa-diálogo $\mathrm{com}^{2}$ os sujeitos, da qual deriva esta narrativa. Trata-se da concepção de trajetórias espaço-temporais, situada como uma ponte conceitual para abordar os processos de des-reterritorialização subalterna vividos por sujeitos, cujos loci de existência fundamental, são os chamados rincões - uma expressão nativa que denomina os espaçostempos mais longínquos e muitas vezes invisibilizados na vastidão dos campos da Campanha Gaúcha ${ }^{3}$.

Desta forma, no primeiro momento desta comunicação, apresentam-se as reflexões sobre as concepções de espaço-tempo como categoria-chave e de território como um conceito para a ciência geográfica, com vistas a delinear uma abordagem acerca das trajetórias espaço-temporais e dos processos de desreterritorialização como componentes conceituais. Já, no segundo momento, busca-se desdobrar como esses componentes se colocam enquanto ferramentas para a reinterpretação de elementos da Campanha Gaúcha, revisitada desde alguns de seus sujeitos subalternizados na trama das relações de poder, para os quais os rincões passam a denotar a condição de territórios em construção, sob uma perspectiva subalterna, o que não excluí outras configurações territoriais passíveis de existência nesses espaços-tempos, porém reivindica seu papel no quadro da diversidade territorial em curso na região.

Do espaço ao território: as trajetórias espaço-temporais e a des-reterritorialização como componentes de abordagem

2 A perspectiva de uma pesquisa-diálogo com, orientou-se em Freire (2012 [1968]), para quem o diálogo é a essência do processo de construção do saber que nasce da relação dos homens entre si, mediatizadas pelo mundo, bem como na proposição feita por Porto-Gonçalves (2008), ao considerar que há um saber que está inscrito no fazer, que é um saber com, ou seja, construído na partilha e convivência dos sujeitos. A partir dessa compreensão e com base na aproximação metodólogica dos estudos de caso ampliados (BURAWOY, 2014), a pesquisa foi realizada, junta a sujeitos e famílias que vivem em rincões situados no interior de municípios da fronteira-oeste do Rio Grande do Sul, particularmente em Alegrete e em áreas limitrofes com os municípios de Rosário do Sul, Santana do Livramento e Quaraí.

3 É importante destacar que o termo Campanha Gaúcha em questão, toma por base a visão de mundo e a linguagem dos sujeitos que vivem em seus campos, ou seja, no seu espaço-tempo rural, o qual expressa com maior força as categorias tradicionais-populares que lhes são constituintes. Ao mesmo tempo, compreendese a implicação mais ampla do mesmo, enquanto diferenciação socioespacial que comporta tanto os processos urbanos quanto rurais e suas distinções quanto a outros recortes regionais. 
Diversos autores no âmbito da epistemologia da ciência geográfica, estabelecem uma distinção, na qual o espaço-tempo ou, o espaço geográfico, se coloca enquanto uma categoria de análise, uma noção mais ampla diante dos demais conceitos desta ciência, como por exemplo, o território. Assim, Harvey (2012 [2006]), considera o espaço-tempo como uma palavra-chave. Raffestin (1993[1980]), afırmou haver um esforço no sentido de se estabelecer um estatuto de noção ao espaço e um estatuto de conceito ao território. Em abordagem mais recente na geografia de língua francesa, Di Méo e Buleón (2005), através da noção de produção social do espaço, enfatizam sua dimensão vivida (le espace vécu), assim, reforçam a clivagem espaço-território, ao afırmar a existência de atores e/ou agentes especializados e atores e/ou agentes territorializados pela sua participação de forma mais intencional (intentionnelle) em um processo espacial.

Na ciência geográfica brasileira, Santos (2002[1996] p.63), ao definiro espaço como "um conjunto indissociável, solidário e também contraditório de sistemas de objetos e sistemas de ações", considerou que para o espaço atingir a condição de uma categoria analítica (ente analítico) independente no âmbito das ciências sociais, seria necessário que os conceitos e instrumentos de análise possuíssem coerência e operacionalidade interna. Desta forma, os conceitos destacados deveriam, ser internos ao objeto correspondente, isto é, ao espaço. Sob essa premissa, o autor elaborou um sistema de categorias internas, as quais propunham refletir sobre a própria ontologia do espaço. Nesse sistema se encontra o desdobramento territorial nos termos de identificação da configuração territorial e da divisão territorial do trabalho ${ }^{4}$, ao lado das demais categorias elucidadas.

Também, para Moraes (2000), há uma distinção epistemológica entre o plano genérico da valorização do espaço e o objeto empírico da formação territorial, enquanto ajuste de foco que visa captar o movimento histórico, na conjunção entre as determinações econômicas e o universo político. Logo, "na historicidade plena dos processos singulares brota a possibilidade de indicar os agentes do processo, os sujeitos concretos da produção do espaço" (MORAES, 2000 p.17). Deste modo, a noção de formação territorial é enfatizada pelo autor como instrumento para compreensão do caráter geohistórico do território.

Por sua vez, Haesbaert $(2009,2010,2014)$ propõe abordar o espaço-tempo ou, espaço geográfico como

4 Dentre as categorias desdobradas, emergiu o conceito de território usado (SANTOS, 1999; SANTOS; SILVEIRA, 2001). Para uma discussão mais aprofundada sobre o desenvolvimento do conceito de território na obra de Milton Santos (19262001), consultar: MORAES. A. C. R. (2013). Território na geografia de Milton Santos. São Paulo: Annablume. categoria-chave e o território como um conceito situado em uma constelação geográfica de conceitos. 0 autor toma como pressupostos, as concepções filosóficas de Deleuze e Guattari (1992), para quem conceitos são problemas postos à uma realidade geohistoricamente situada. Os mesmos, não se encontram isolados pois, remetem-se uns aos outros. Desta forma, para Haesbaert (2014), as problemáticas constituem o foco central, dos conceitos, que sempre colocam em evidência determinadas questões ou relações. Assim, afırma que em geografia, quando se enfatiza ou focaliza o espaço mediante as questões ligadas às relações ou práticas de poder, de alguma forma o espaço é referido enquanto território (HAESBAERT, 2014).

Outras contribuições importantes neste debate, residem nas proposições de Souza $(1995,2009,2013)$, sobretudo em sua preocupação quanto a confusão existente entre o conceito de território e o de substrato espacial material, o qual na sua visão, serve de referência para os processos de territorialização. Assim, Souza (2013), ao permear as discussões sobre o poder, com destaque para a perspectiva filosófica de Castoriadis (1982), reafirma os elementos de sua interpretação sobre o território, na qual, antes de ser considerado um espaço concreto, territórios são vistos como relações sociais projetadas no espaço, são "um campo de forças, as relações de poder espacialmente delimitadas e operando, destarte, sobre um substrato referencial" (SOUZA, 1995 p.97).

Diante do exposto, nota-se na abordagem dos referidos autores que o espaço enquanto categoria-chave e o território como conceito, respectivamente, tratam de uma concepção de espaço-tempo relacional, que remete na instância filosófica, ao conceito de mônada em Gottfried W. Leibniz (1646-1716), o qual permite compreender o espaço como um conjunto de relações, como um processo, conforme interpreta Harvey (2012 [2006], p.12), "processos não ocorrem no espaço, mas definem seu próprio quadro espacial. 0 conceito de espaço está embutido ou é interno ao processo". Nessa abordagem deve-se, focar na relação espaço-tempo, mais do que no espaço isoladamente (HARVEY, 2012[2006]). Assim, torna-se possível compreender a inscrição do tempo no espaço conforme o aporte de Lefebvre (2013 [1974]), segundo o qual o histórico e o diacrônico, se inscrevem incessantemente sobre o espaço, como em uma espécie de quadro. Mas, também, os traços incertos deixados pelos acontecimentos pretéritos não são os únicos que existem no espaço. Há inda, a inscrição em ato da sociedade.

Em sentido semelhante mas, com base, sobretudo, na crítica à filosofia de Henri Bergson (1859-1941) e a 
característica de estase que a mesma incute ao espaço, Massey (2008) enfatiza como o espaço fornece as condições para existência das relações temporais. Nesta significação, o tempo corresponde à dimensão da mudanç $a^{5}$ e o espaço à dimensão do social como produto de inter-relações; esfera da possibilidade da existência da multiplicidade, na perspectiva da pluralidade contemporânea (coetaneidade) e sempre em construção (MASSEY, 2008). Concepção que visa estabelecer um imaginário alternativo à constelação de conceitos atribuídos ao espaço, veiculado às ideias de estase, fechamento e representação, por diferentes correntes filosóficas.

É notável que são justamente as concepções de espaço-tempo relacionais que têm permitido à ciência geográfica adentrar com maior acuidade ao conceito e às questões territoriais nas últimas décadas. Raffestin (1993[1980] p.144), em sua afirmação de que os territórios são espaços, por primazia, políticos, ou seja, "um espaço onde se projetou um trabalho, seja energia e informação, e que por consequência, revela relações marcadas pelo poder", situa sua perspectiva territorial no que denomina de problemática relacional, na qual aufere que a existência é tecida por relações.

Neste âmbito Raffestin (1993[1980]) recupera a tese do fetichismo da mercadoria em Marx (2013 [1867]), tese que demonstra que toda mercadoria, em sua aparência, denota ser uma coisa em si mesma, mas em sua essência é constituída por um ato, no qual está implícito uma relação. Ainda, Raffestin (1993[1980]), ao optar pela problemática relacional acredita que as relações possibilitam tornar inteligível o poder e suas manifestações espaciais. Nessa intermediação, entre o espaço e o poder, adere a tese da imanência do poder em Foucault (1999[1976]), para quem, o poder não está em posição de exterioridade quando às demais relações - econômicas, políticas, de gênero e sexualidades, por exemplo, mas sim é um elemento constituinte das mesmas.

Também, Sack (2011[1986]) na literatura de língua inglesa considera que a territorialidade humana é a forma espacial primária que o poder assume, em suas múltiplas escalas e temporalidades, entre as diferentes formas de organização espacial dos povos e nações, do lar à grande empresa capitalista. 0 autor trabalha mediante uma concepção relacional do espaço-tempo, a qual é marcada pela intencionalidade das ações nas relações espaciais. Pois, "interação humana, movimento e contato são também casos de transmissão de energia

5 Di Méo e Buléon (2005), contribuem nessa discussão ao afirmar que a temporalidade se funda a partir de duas constatações de nosso vivido. a) A percepção da mudança, desde nossa relação com seres e lugares; B) A onipresença de nossa memória e das lembranças que a habitam. e informação, para se afetar, influenciar e controlar as ideias e ações de outros e o acesso deles a recursos" (SACK, 2011 [1986] p.87-88).

Ainda, o autor aponta para os contextos históricos em que as organizações e os significados espaciais se desenvolvem, assim identifica os diferentes usos que se podem fazer da territorialidade. Sua concepção de poder está mais próxima das afirmações de Weber (1999[1920]), no sentido de uma ação que deseja influenciar a ação de outras pessoas e de fato as influências. Weber (1999 [1920]), expõe a ideia do poder como um mandado que pode ser cumprido por meio da conviç̧ão de sua conformidade, por sentimentos de obrigação, por medo, por vantagem pessoal ou costume. Essa compreensão é traduzida territorialmente por Sack (2011[1986]), nos elementos influenciar, afetar e controlar que constituem a territorialidade e desdobram seus usos.

Ao empregar e densificar algumas das concepções espaço-temporais e territoriais mencionadas, Haesbaert (2004) afirmou através do aporte lefebvreano, que o território "(...) enquanto relação de domínio e apropriação sociedade-espaço, desdobra-se ao longo de um continuum que vai da dominação político-econômica mas "concreta" e "funcional" à apropriação mais subjetiva e/ ou "cultural-simbólica" (HAESBAERT, 2004 p.95-96). Este caráter de domínio e/ou apropriação do espaço, depende sempre de cada grupo, classe social ou instituição, em seu contexto geohistórico e na multiplicidade das relações de poder em que estão inseridos. Desta forma, o autor propõe uma concepção integradora do território, que é multidimensional, multiescalar e processual, pois com base em Deleuze e Guattari (2000[1980]), interpreta como os territórios se fazem e refazem, cada vez mais no e pelo movimento, bem como em lógicas espaciais reticulares.

Ainda, ao aprofundar-se na interpretação das tecnologias de poder trabalhadas por Foucault (2014 [1975], 1999[1976], 2008 [1978]), como a soberania, a disciplina e o biopoder, bem como apoiado nos desdobramentos realizados por Agamben (2002), principalmente, a respeito da tanatopolítica, Haesbaert (2014) elucida múltiplos processos territoriais contemporâneas, como a in-segurança e o des-controle dos territórios, as territorialidades de exceção, os processos de contenção e contornamento territorial vividos pelos grupos subalternos que no limite de suas existências, reinventam seus territórios e territorialidades também, através de sua capacidade de resistência, pois como diria Foucault (1999[1976] p.91), “lá onde há poder há resistência".

Diante do exposto, pode-se inferir que a abordagem territorial e a análise de seus processos, se colocam como 
um recurso de método ao pesquisador, para focalizar relações constituintes da multiplicidade espacial, tais como o poder. Entretanto, na passagem do espaço ao território, há um caminho a trilhar, como na vida real, uma ponte se faz necessária para ultrapassar o perigo das águas e atingir a outra margem terrena do rio. De forma análoga, no plano epistemológico uma ponte se faz necessária para ultrapassar a vaguidade da categoria espaço-tempo para adentrar no terreno, tanto firme quanto movediço, das relações territoriais. Nesta lógica, considera-se um caminho profícuo para este intento, situar a abordagem das trajetórias espaço-temporais dos sujeitos como componente de ligação para compreender os processos de des-reterritorialização formadores dos territórios e das territorialidades.

Trajetórias espaço-temporais e des-reterritorialização em debate

Para Massey (2008), o espaço é abordado a partir de categorias como a multiplicidade, a heterogeneidade, 0 caráter vivido e a abertura. Nesse olhar, o espaço então, não é "um todo já-interconectado, mas um produto contínuo de interconexões e não-conexões. Assim, ele será sempre aberto e inacabado" (MASSEY, 2008 p.160). Por isso, é visto como uma simultaneidade dinâmica, desconectado por novas chegadas, indeterminado pela construção de novas relações. Desta concepção retirase os fundamentos para abordar as trajetórias dos sujeitos, enquanto estórias-até-agora, em processos de mudança espaço-temporal conforme Massey (2008), elemento que possibilita refletir sobre os processos de des-reterritorialização.

Neste ângulo, o olhar em questão se encaminha na direção de uma visão rizomática do mundo, na qual o espaço é constituído de conexões e rupturas, de linhas de fuga, de aberturas na imanência do devir (DELEUZE; GUATTARI, 2000 [1980]). De tal perspectiva, deriva uma concepção de território, na qual o mesmo é feito de processos de des-reterritorialização, pois, produzir linhas de fuga enseja um movimento de desterritorialização, que ao reencontrar um novo território, ou seja, em um movimento de territorialização a se refazer - produz a reterritorialização. A questão foi retomada por Haesbaert (2004) no diálogo com os referidos autores, para reafirmar uma perspectiva processual, onde as desterritorializações e reterritorializações são componentes dos territórios. Também, muito grupos sociais podem vivenciar o que Haesbaert (2004) chamou de desterritorialização in situ, ou seja, podem estar "desterritorializados" sem um deslocamento físico, ou níveis de mobilidade espacial pronunciados, bastando para isso que vivenciem uma precarização de suas condições básicas de vida e ou/ negação de sua expressividade simbólico-cultural.

Nessa perspectiva processual, também é significava a contribuição de Raffestin (1988), acerca da territorialidade humana, enquanto uma dinâmica feita de continuidade e descontinuidade, o que promove a territorialização-desterritorialização-reterritorialização (T-D-R). Nesse contexto, a desterritorialização representa uma crise de limites, uma crise de relações no contexto da territorialidade anterior e a reterritorialização, como a nova territorialidade, se apresenta como um conjunto novo de relações dos sujeitos entre si, com a exterioridade e a alteridade (RAFFESTIN, 1988).

Diante do exposto, se compreende que entre a linha de fuga e a linha de chegada (expressão cunhada para designar a reterritorialização) - ou nos processos de permanência em um território - existem espaçostempos em construção, nos quais as trajetórias espaçotemporais dos sujeitos são um dos componentes para compreender os processos de des-reterritorialização e as territorialidades de um território. Focalizá-las, pois, representa a elaboração de uma ponte conceitual, desde a perspectiva de Deleuze e Guattari (1992).

Para os referidos autores, todo conceito possui componentes e se definem por eles.

Com efeito, todo conceito tendo um número finito
de componentes bifurcará sobre outros conceitos,
compostos de outra maneira, mas que constituem
outras regiões do mesmo plano, que respondem a
problemas conectáveis, participam de uma co-criação
(DELEUZE; GUATTARI, 1992 p.26).

Logo, traçado um plano determinável, se passa de um conceito ao outro, afirmam Deleuze e Guattari (1992), como por uma espécie de ponte. É desta maneira que se sugere o estudo das trajetórias dos sujeitos no espaçotempo, como uma ponte conceitual que contribui para a travessia analítica dos componentes que constituem a categoria espaço-tempo, ao terreno conceitual das relações territoriais. Pois, os conceitos enquanto uma heterogênese, uma ordenação de seus componentes por zonas de vizinhança, onde esses se situam em um estado de sobrevoo, passando-o e repassando-o como em um ritornelo de uma obra musical, possuem uma consistência interna (endoconsistência), dada pela inseparabilidade de seus componentes (DELEUZE; GUATTARI, 1992).

A exemplo do que acontece na abordagem territorial, na qual não se compreende a formação de um território, sem a apreensão dos processos de desre-territorialização e do exercício de territorialidades (multi-trans-territorialidade), que derivam das relações 
de domínio e apropriação do espaço e desenham a materialidade e a identidade territorial, conforme apreendem os trabalhos de Haesbaert (2004, 2009, 2014). Esses elementos vão ao encontro da tríade relacional - território, territorialidade, territorialização proposta por Porto-Gonçalves $(2002,2003)$. Os mesmos são parte dos componentes da endoconsistência do conceito de território.

Porém, cada conceito "tem igualmente uma exoconsistência, com outros conceitos, quando sua criação implica a construção de uma ponte sobre o mesmo plano. As zonas e as pontes são as junturas do conceito" (DELEUZE; GUATTARI, 1992 p.28). É neste significado que se entende a trajetória espaço-temporal dos sujeitos como ponte conceitual, ela é enquanto componente conceitual, o ponto de intermediação entre a exoconsistência do conceito território que se estabelece na sua relação com os movimentosprocessos no espaço-tempo; ao mesmo tempo, quando tratada enquanto produto e produtora de relações de poder no espaço-tempo, o estudo das trajetórias contribui para atingir o plano da consistência interna do conceito de território, dada pelos processos de des-reterritorialização e exercício das territorialidades.

Desta forma, considera-se mister as proposições de Massey (2008) e Cresswell (2006), quanto às trajetórias e à mobilidade. Trajetória é um elemento que remete ao caráter de coetaneidade do espaço, no qual uma pluralidade de trajetórias, uma simultaneidade de estórias-até-agora, coexistem, assim tanto trajetória, quanto estória, significam enfatizar um processo de mudança em um fenômeno (MASSEY, 2008). Neste caso, a mudança é espaço-temporal, envolve o movimento no espaço-tempo ou, mais do que isso, diz respeito à produção de mobilidades conforme Cresswell (2006). Logo, como componentes conceitos que se aproximam nas perspectivas de Massey (2008) e Cresswell (2006), trajetória e mobilidade abrangem as mudanças de temporalidades e espacialidades, a partir da produção e percepção das relações sociais, em diferentes escalas. Relações que são produto e produtoras de poder e significados (CRESSWELL, 2006). Ademais, a temporalidade, também aciona o campo das memórias e lembranças dos sujeitos (DI MÉO; BULEÓN, 2005).

Dessa maneira, mais do que viajar sob uma superfície, quando se está em um trem, por exemplo, ou deslocar-se do ponto A para o B, em termos de trajetória e mobilidade, não se viaja ou se cruza o espaço, "na medida em que o espaço é produto de relações sociais, você também está ajudando, embora, neste caso, de maneira bem mais sutil, a alterar o espaço" (MASSEY, 2008 p.175). De forma semelhante Cresswell (2006), enfatiza que há algo a mais na linha de passagem do ponto A para o $B$, qual seja, a produção de um tempo-espaço social. "Mobilidade, como produto social, não existe em um mundo abstrato do tempo e espaço absoluto, mas de um mundo significativo do espaço social e do tempo social" (CRESSWELL, 2006 p.5 [tradução livre]).

No campo sociológico, Bourdieu (1996) sugere, a noção de trajetória como uma série de posições sucessivamente ocupadas por um mesmo agente ou grupo, em um espaço em devir e submetido a transformações constantes. Sugestão que vai ao encontro das proposições de Massey (2008) e Cresswell (2006), acerca da trajetória e da mobilidade em suas transformações, que são produto e produtoras de relações no movimento, tanto quanto pela própria natureza da qualidade do devir espacial. 0 autor, ainda enfatiza a necessidade de compreender a trajetória dos sujeitos nos estados sucessivos do campo ao qual se desenrolou, assim como em relação aos demais agentes envolvidos no mesmo campo e em suas defrontações no espaço (BOURDIEU, 1996)

Assim, o que Bourdieu (1996) vê como as sucessivas posições no campo, vê-se aqui, como as sucessivas relações no espaço-tempo. O próprio Bourdieu (1996), aponta que seria um absurdo, por exemplo, "tentar explicar um trajeto no metrô sem levar em conta a estrutura da rede, isto é, a matriz das relações objetivas entre diversas estações" (BOURDIEU, 1996 p.81). Por conseguinte, o campo das relações pode ser traduzido geograficamente no espaço-tempo relacional construído pelas trajetórias dos sujeitos, no contexto das relações de poder em que estão inseridos. Então, o defrontarse no mesmo espaço corrobora a trajetória como a possibilidade do encontro segundo Massey (2008), tanto quanto à dimensão da imanência do poder em suas correlações de força no espaço-tempo, conforme a matriz interpretativa de Foucault (1999 [1976]).

Com base nessa reflexão abordar-se-á, no item a seguir, como no regime territorial vigente na Campanha Gaúcha múltiplas trajetórias coexistem no seu espaçotempo, ainda que subalternizadas pela hegemonia e dominação de determinados sujeitos. Nesse contexto, dentre os sujeitos des-reterritorializados na subalternidade, os chamados rincões da Campanha Gaúcha têm se constituído em um de seus espaçostempos de vida, marcados pelos paradoxos da precariedade e da r-existência - a forma de resistência

6É importante mencionar que para Bourdieu (2005), a noção de campo é empregada no sentido de definir um espaço de relações, ou um campo de forças onde diferentes agentes atuam. Trata-se de uma representação do mundo social, na forma de um espaço multidimensional baseado nos princípios de diferenciação ou de distribuição, constituído de um conjunto de propriedades que atuam no universo social considerado. Nesse espaço, os agentes sociais podem ser definidos de acordo com as posições que ocupam. 
que se faz através das matrizes de saber inscritas nas existências de seus protagonistas (PORTO-GONÇALVES, 2006), ensejando uma produção territorial marginal e muitas vezes invisibilizada ante o poder circundante.

A Campanha Gaúcha é revisitada desde
sujeitos subalternizados: trajetórias e enlaces
territoriais

O regime territorial em curso na Campanha Gaúcha, remete a uma escala espaço-temporal de longa duração conforme a noção geohistórica de Braudel (1990 [1958]). Assim, opta-se por abordar seus fundamentos e seu caráter, mais do que resgatar sua genealogia. Logo, se destaca que o regime territorial em questão é produto da colonialidade, enquanto uma estrutura articulada e heterogênea de relações de poder que agem em cada âmbito da existência social, segundo Quijano (2007), os quais são: 1) o trabalho e seus produtos; 2) a natureza e seus recursos de produção; 3 ) o sexo, seus produtos e a reprodução da espécie; 4) a subjetividade, seus produtos materiais e intersubjetivos, incluindo o conhecimento; 5) a autoridade e seus instrumentos. No processo, as formas históricas de trabalho subordinam-se ao capital; do mesmo modo que nos outros âmbitos, o sexo em relação à família burguesa, a subjetividade em relação à racionalidade moderna e a autoridade articulada ao Estado-nação.

Na Campanha Gaúcha a colonialidade se constituiu através da dominação de bens naturais, como a terra e o gado oriundo das vacarias ${ }^{7}$, sob a forma de grandes propriedades - as estâncias, destinadas ao aprisionamento do gado para reprodução e comercialização; pela exploração do trabalho livre, escravo e familiar, subordinado aos interesses econômicos dos estancieiros; por um regime de autoridade sustentado através de relações de domínio pessoal e da violência pelos considerados senhores da terra, ante os demais sujeitos sociais; bem como a serviço do Estado territorial no Brasil, sobretudo na defesa de suas possessões meridionais.

Tal processo, emergiu em um contexto de militarização pelas disputas coloniais e conduziu a um modelo de sociedade fundado em heterarquias, que de acordo com Castro-Gómez e Grosfoguel (2007), constituem uma rede de relações, entrelaçadas pelos regimes de poder, onde não há uma determinação em última instância e tampouco o domínio de dispositivos autônomos. Desta

7 Vacarias: expressão que corresponde ao imenso rebanho de gado "xucro" (não domesticado), oriundo das estâncias de criação de gado (vacuns e muares) implementadas pelos os padres jesuítas espanhóis em suas reduções, as quais foram abandonadas diante das ameaças dos bandeirantes paulistas nas disputas pelos territórios meridionais no período colonial, que configuraram a atual delimitação da região sul do Brasil. forma, na Campanha Gaúcha, o racismo, o patriarcalismo e o machismo tornaram-se as referências nas relações étnicas e de gênero; tanto quanto, no enredo dessas relações houve um processo de subalternização entre os considerados senhores da terra e os denominados de intrusos ou, sujeitos de segunda classe (como os povos indígenas, camponeses, escravos, peões ${ }^{8}$, as mulheres, dentre outras categorias sociais), o que produziu uma profunda clivagem na socioespacial.

Nesse contexto, o genocídio dos povos indígenas (com destaque para as nações Charrua e Minuanos) e suas formas de existência; os produtos do trabalho familiar e os sujeitos camponeses; os produtos do trabalho livre dos peões e suas famílias; a exploração do trabalho do escravo e os sujeitos cativos, tanto quanto as riquezas naturais (campos e gado), subordinaram-se nas relações de poder sustentadas no regime da soberania e na violência ${ }^{9}$ dos senhores da terra. Nesse sentido, o instituto da soberania, que representa uma tecnologia de poder segundo Foucault (1999 [1976]), a qual se exerce sobre a terra e seus produtos, permitindo extrair dos corpos bens e riquezas, mais do que tempo e trabalho, foi o instrumento que tornou a figura do estancieiro em soberano, com homem branco, patrão e herói militar, figura inconteste no domínio territorial, ao mesmo tempo, responsável pela dimensão racista, classista, patriarcal e machista que fundamenta o regime territorial na sociedade e no espaço da Campanha Gaúcha.

Oriundo de tais processos, o regime territorial, de saber e de poder, calcou-se na territorialização estancieira num primeiro momento (até o início do século XX), mas passou por alterações em seus agentes e nas formas de exercício do poder, sobretudo com o ingresso e a territorialização de vetores do agronegócio na Campanha Gaúcha (a partir da segunda metade do século XX e início do século $\mathrm{XXI})^{10}$, o que promoveu a formação de uma espécie de bloco no poder - conforme a abordagem de Poulantzas (1980) - entre estancieiros e agronegociantes (muitas vezes personificados em um único sujeito). As relações de poder, por sua vez, transfiguraram-se na tecnologia do biopoder, um poder que age sob as condições de vida da população enquanto espécie, conforme Foucault (2008 [1978]).

8 Peões da Campanha Gaúcha: são os trabalhadores assalariados que vivem da venda de sua força de trabalho aos estancieiros e fazendeiros. Suas tarefas residem fundamentalmente no manejo do gado no campo. Na linguagem tradicional-popular peão é aquele que vive da lida campeira.

9 Muito embora o poder e a violência devam ser considerados fenômenos distintos, conforme Arendt (1985 [1970]), geralmente apresentam-se juntos. A violência funciona, segundo a filósofa, como o último recurso do poder, ou seja, emerge justamente para assegurá-lo em seus momentos de crise.

10 Conforme Heidrich (2000 p.104), "relativizam esse perfil, embora não tenham repercutido a ponto de modificar a estrutura econômica da região e evitar a situação de crise, a indústria das cidades de Rio Grande e de Pelotas, a rizicultura irrigada do litoral lagunar e das várzeas do Jacuí, Ibicuí e Uruguai, entre outras". 
Todavia, se ocorreu a formação de um regime territorial hegemônico-dominante, ele se fez desde a subalternização de múltiplos sujeitos e de suas territorialidades. Por conseguinte, o caráter territorial deste regime reside na paulatina e compulsória desreterritorialização daqueles considerados intrusos e/ ou sujeitos de segunda classe. Ou seja, trata-se de uma des-reterritorialização subalterna, na qual tais sujeitos podem ser entendidos como aquele(a)s que sofrem as múltiplas sujeições existentes no corpo social em função de um poder heterônomo, de acordo com a linha interpretativa de Foucault (2005[1976a]); seu imaginário social, suas memórias históricas e saberes locais estão subalternizados, ante os projetos globais, complementase através da visão de Mignolo (2003); se situam, pois, em relações de direção e dominação, de mando e obediência, de hierarquia e subordinação, mas também de resistência (GRAMSCI, 2014[1934]).

Sob esta condição subalterna, estavam postas as contingências da des-reterritorialização para esses sujeitos, que na produção de suas linhas de fuga passaram a ocupar frações de terras nos fundos de campo, que possuíam uma incorporação e conhecimentos tênues por parte dos agentes hegemônicos-dominantes, tratavamse dos espaços-tempos mais invisibilizados e afastados dos povoados, muitas vezes inóspitos por seus atributos físicos. Constituíam verdadeiras fronteiras no interior da Campanha Gaúcha como atribui Osório (2016). Já, para os agentes do regime territorial hegemônico-dominante configuram uma espécie de fundo territorial (MORAES, 2013).

Nesta contingência, também ocorreu a ocupação dos postos e dos corredores ${ }^{11}$ construídos pelos estancieiros para o manejo das tropas e comercialização do gado. Ainda, diante do avanço do regime territorial, a perspectiva de permanecer em um espaço próximo, já habitado por familiares ou conhecidos, tornou-se limitada. Foi possível, somente mediante uma condição subordinada aos estancieiros e/ou agronegociantes, processo indicativo de uma desterritorialização in situ, enquanto precária condição de uso e apropriação do espaço, frente ao exercício de um poder que almejava manter os sujeitos cativos.

11 Postos: remetem as construções que demarcavam os limites das grandes propriedades antes da segunda metade do século XIX, momento em que os campos passaram a ser cercados na Campanha Gaúcha. Nos postos eram empregados peões e suas famílias, responsáveis pela vigília e manejo dos rebanhos dos estancieiros. Muitos desses peões conseguiram se apropriar desses espaços no contexto do movimento de cercamento dos campos, tanto em função da reivindicação de dívidas trabalhistas, quanto das relações de domínio pessoal empreendidas pelos estancieiros. Já a expressão corredores - remete aos caminhos abertos pelas tropas de gado nos campos sulinos desde o período colonial, com o objetivo de comercialização. Muitos desses corredores transformam-se em estradas vicinais e/ou municipais que dão acesso as diferentes localidades e aos espaços urbanos. A ocupação das faixas de terras entre os corredores e as cercas das grandes propriedades, também foi uma das alternativas de sobrevivência, encontradas nos processos de des-reterritorialização subalterna.
Esses processos deram novos sentidos às áreas que eram reconhecidas no passado como rincões, expressão de origem castelhana que designava os locais mais afastados das estâncias, circunscritos por córregos e mata, utilizados para o manejo do gado, no período em que as propriedades ainda não eram cercadas. Em meio aos processos de des-reterritorialização subalterna, foram justamente essas áreas, longínquas e invisibilizadas, as quais, aos poucos tornaram-se residuais ao domínio estancieiro, que passaram a ser ocupadas pela multiplicidade subalterna e assim os rincões adquiriram uma nova significação como a morada ou a querência (espaço onde alguém nasce, cresce e desenvolve sentimentos de afeto pelo mesmo) de sujeitos como: peões e camponese(a)s, comunidades quilombolas e remanescentes das populações originárias (mais raramente), dentre outros.

Destarte, nos rincões se encontram uma multiplicidade de trajetórias forjadas pelos sujeitos no contexto de sua des-reterritorialização, cuja riqueza contribui para o entendimento da diversidade territorial no contexto da região da Campanha Gaúcha, ainda que os mesmos sofram, cada vez mais, com as iniciativas aviltantes da territorialização estancieira e do agronegócio. Neste sentido, com base na pesquisa-diálogo com os sujeitos dos rincões estudados, abordam-se duas trajetórias espaço-temporais representativas ${ }^{12}$ de alguns enlaces territoriais presentes nos rincões. Seus enredos e os codinomes utilizados, foram extraídos de canções nativistas de relevância no contexto regional.

O Velho Mangrulho dá seu testemunho na geohistória territorial

A expressão Mangrulho vem do título da canção 0 Mangrulho ${ }^{13}$ e representa um termo militar. Trata-se de uma construção elevada que se faz em um terreno, para observação das tropas inimigas, uma espécie de mirante. Na canção O Mangrulho, o termo é personificado, na figura de um sujeito que vive e observa os processos de mudança em seu território. Atribui-se esse codinome para reportar-se a trajetória de um dos moradores mais antigos de um dos rincões estudados. Ele afirma: - sou criolo aqui do rincão, nasci, me criei e fiquei velho aqui.

12 A escolha das respectivas trajetórias é parte de um contexto de convivência e diálogo com diversos sujeitos e famílias que vivenciam a realidades dos rincões estudados, cujas aproximações foram realizadas através de observações participantes, entrevistas e diálogos, bem como registros de campo. 0 critério de escolha das narrativas, segue a premissa metodológica apontada por Burawoy (2014), segundo a qual é possível realizar aproximações com os fenômenos mais amplos (macroprocessos), com base na análise entre microforças, ao mesmo tempo em que se percebe nas relações mais amplas, a presença dos contextos locais, ou seja, dos microfundamentos, agindo e influenciando-as.

130 Mangrulho. Interpretes: Jorge André e Grupo Uruches. Compositores: ALVES, K.; VASCONCELLOS, M. A. In.: Lp.10a Califórnia da Canção Nativa do RS. Porto Alegre: K-Tel, 1980. 
Desta forma a metáfora da canção contribui para pensar a trajetória de um sujeito que não apenas observa o tempo, mas constitui e vivencia uma temporalidade, percebendo suas mudanças, produzindo movimentos no espaço, representações e significados como aponta Cresswell (2006) acerca da mobilidade. Essa trajetória espaço-temporal, revela que, não são apenas histórias enterradas que estão no espaço, mas histórias em realização (MASSEY, 2008).

Um primeiro aspecto a ser destacado na trajetória do senhor Mangrulho, está na percepção de viver em uma zona, expressão também presente em outros relatos, assim como na redondeza. Esses referenciais remetem a um dos elementos básicos da produção social do espaço, as áreas. Parte do que Raffestin (1993 [1980]) conceituou como o essencial visível das práticas espaciais, as malhas, assim como os nós e as redes, que de algum modo se imprimem no espaço-tempo e constituem um território. Um segundo aspecto, diz respeito à sua formação de classe subalterna, enquanto trabalhador que nas suas palavras não refugava serviço, desenvolvendo atividades de alambrador, tosador e cuidador de campo ${ }^{14}$, constituiu-se, desta maneira em um trabalhador temporário, que se empregava em serviços específicos e esporádicos dentro de uma propriedade rural, bem como na condição de peão, com vistas à venda de sua força de trabalho para a reprodução da sua existência e de sua família. Sua trajetória atesta uma vida de muito trabalho e só assim adquiriu a diminuta propriedade onde vive, juntamente com seus entes mais próximos, coadunando uma posição de classe entre a condição de peão e camponês.

$\mathrm{Na}$ medida em que se compreende a trajetória como um processo em que se produzem relações significativas, através das representações elaboradas, como problematiza Cresswell (2006), as quais se traduzem em experiências incorporadas ${ }^{15}$; o corpo enquanto escala se conecta a outras escalas. Assim, o corpo do senhor Mangrulho foi relacionando-se com diferentes espaços em sua trajetória, da casa à estância, do campo à cidade, da Campanha até outras regiões do Rio Grande do Sul, esses processos são constitutivos de sua des-reterritorialização. Desta maneira, como destaca Massey (2013 [2005] p.175), "você é parte do processo

14 Alambrador: deriva da palavra alambrado, ou também aramado, tipo de cerca feita de arame farpado. Alambrador ou Aramador, é o trabalhador especialista na construção de cercas nas propriedades rurais da Campanha Gaúcha. Tosar ou Esquilar é a atividade de aparar a lã das ovelhas ao final da primavera, preparando-as para o calor do verão. Cuidar de Campo é a atividade desempenhada pelo peão de estância, que vai do manejo do gado, transferindo-o para áreas de melhor pastagem e observação do rebanho, até o tratamento de zoonoses, a vacinação, a castração e marcação dos animais.

15 Esta noção de experiência incorporada também permite o diálogo como o conceito de habitus em Bourdieu (2009), na medida em que este significa o conjunto das disposições incorporadas em um campo relacional, através das quais os agentes tendem a traduzi-las em um conjunto de práticas. constante de estabelecer e quebrar elos, que é um elemento na constituição de você mesmo". Deste modo, através das representações do espaço-tempo criadas em sua trajetória, os significados sobre a Campanha Gaúcha se transfiguraram para o Mangrulho.

Assim, viver na Campanha Gaúcha, apesar das dificuldades, é visto como algo bom, melhor do que viver na cidade, tanto em termos econômicos quanto sociais. Esses significados são enunciados através de categorias da prática, incorporadas ao saber dos sujeitos. Na Campanha se tem mais bondade, se vive mais folgado. A noção de viver mais folgado significa na linguagem dos sujeitos, gastar menos dinheiro, além do mais, na Campanha, se pode plantar e criar animais, o que contribui para o autoconsumo e reprodução familiar. Por sua vez, o significado de bondade da Campanha trata da representação do bom convívio na relação com os vizinhos e com a própria natureza.

Esse significado deve ser entendido em sua relacionalidade com a percepção que os moradores dos rincões possuem acerca da violência, do caos urbano e de suas restrições de circulação, o que não significa que estes espaços estejam isentos de tais problemáticas. Mas, o significado de bondade se aproxima de um imaginário de bem viver ${ }^{16}$ nos rincões, o qual se sobrepõe a significação construída acerca do espaço urbano. Está presente nessa concepção, a compreensão de que a vida na Campanha seria mais livre, porém trata-se de uma liberdade de movimento conforme a leitura de Cresswell (2006), que representa a possibilidade de poder ir para onde se deseja em meio ao vasto ambiente, uma expressão nativa acerca do tema é correr campo a fora. Também, nas práticas que derivam desse imaginário, situam-se relações de reciprocidade, amor ao ambiente e seus entes, bem como luta por margens de autonomia.

Não obstante, atento ao seu tempo (passado e presente), o Mangrulho descreve sua percepção da mudança espaço-temporal de uma maneira crítica. Seus referenciais de temporalidade são: de primeiro, quanto tudo estava bem e o agora que caracteriza como uma anarquia muito grande. Essas referências de temporalidade estão relacionadas aos elementos fundamentais de reprodução de sua vida em sociedade, como alguém responsável pela produção e consumo de alimentos. Sua fala faz menção a uma época em que se tinha de tudo, se criavam animais, plantavam diversos alimentos e como agora isso deixou de acontecer,

16 Cabe destacar que a expressão bem viver é oriunda das lutas dos sujeitos subalternos na América Latina e possui um conteúdo muito mais amplo do que as nuances presentes nos rincões da Campanha Gaúcha, pois, concerne a uma forma de reconstrução da vida sob os preceitos da justiça, dignidade e autonomia. De acordo com Quijano (2014), o bien vivir ou buen vivir, representa uma outra forma de existência social, baseada em práticas sociais distintas das imposições da colonialidade global do poder. 
ficando apenas o som dos motores das conduções (carros, caminhões, tratores, motos).

Trata-se da percepção da perda de diversidade que a Campanha Gaúcha vem sofrendo, sobretudo entre os camponeses da região que se caracterizam historicamente pela condição de ser pastores elavradores, como a trajetória do próprio Mangrulho atesta. Resta, em sua visão do espaço-tempo presente, o agora, nas suas palavras: - a tecnologia, dos duzentos mil tratores e só essas lavouras aí. Trata-se então da percepção do senhor Mangrulho quanto ao avanço do agronegócio na região, evidenciada claramente em sua fala, pois já não se planta o que era cultivado antes. Ou seja, percebe a expansão das monoculturas na Campanha Gaúcha, principalmente de arroz e soja nas últimas décadas.

O uso de venenos (agrotóxicos), também é mencionado, o que o calejado Mangrulho compreende como um risco à vida, uma forma de matar o pessoal como expôs. Além disso, esta forma de produção serve aos graúdos (menção aos grandes produtores), que só desejam o dinheiro do pessoal, o que revela sua compreensão da incessante busca pelo lucro oriunda desse sistema. Dessa forma, é possível ver, através da trajetória do ancião Mangrulho da Campanha Gaúcha, a manifestação de uma linguagem crítica ao poder, na medida em que se compreende nesta narrativa, a elaboração de um discurso oculto de um sujeito subordinado, que vem à tona, fora de cena, fora do campo de observação direta dos detentores de poder (SCOTT, 2013 [1990]).

Por fim, cumpre destacar que o resgate desta trajetória contribui para adentrar na dimensão geohistórica de um território, na medida em revela como um sujeito capta e participa das mudanças nas escalas espaçotemporais. Da mesma forma, traz à tona representações e significados que se inscrevem nos processos de apropriação do espaço, inerentes a des-reterritorialização subalterna vivada pelos sujeitos dos rincões estudados na Campanha Gaúcha. Sua apreensão também, contribui na reflexão sobre as questões territoriais, quanto a natureza da dominação capitalista/colonial nesse contexto e suas conotações bio-tanatopolíticas, oriunda dos dispositivos de poder de vida e de morte, conforme Foucault (2008 [1978]) e Agamben (2002), diante do discurso sobre o avanço e as reconfigurações vigentes no regime territorial, identificadas pelo senhor Mangrulho. Também, diz respeito a percepção dos dispositivos de poder que precarizam a vida nesses rincões. Territórios marcados pela ambivalência entre a subalternidade e a r-existência.
A Negra Maria e o Peão Pacácio: os laços do encontro na trama territorial

A canção nativista Romance na Tafona ${ }^{17}$, é acionada como forma ilustrativa para abordar a trajetória de um casal de moradores que possui fortes laços familiares entre si, bem com um apego muito significativo ao seu espaço-tempo imediato. Neste caso, se a trajetória do longevo Mangrulho revelou a potência da estória que se faz até agora, a trajetória da Negra Maria e do Peão Pacácio, codinomes atribuídos através da canção, revela a força do encontro, do caráter coetâneo do espaço, do viver lado a lado no convívio um com o outro. Traz à tona a produção de inter-relações, oriunda do encontro no espaço-tempo (MASSEY, 2008).

É assim que se ilustra o enlace entre Negra Maria com - Peão Pacácio, moradores de um corredor nos rincões da Campanha Gaúcha. A tafona ${ }^{18}$ é o espaço metafórico no plano imaginário das representações, mas que traduz o espaço real dado pelo encontro das duas trajetórias distintas. Logo, o romance que iniciou em um baile de Campanha, perdura em uma longa trajetória de vida, a qual representa a constituição dos elos mencionados por Massey (2008). A circunstância do encontro, revela ainda, a força de como o acaso faz o espaço, pois o inesperado promoveu o encontro entre Pacácio e Maria, cujas famílias não se conheciam e moravam distantes. Portanto, é desse acaso que brotam as forças das relações de um com o outro e com a exterioridade.

Maria é oriunda de uma família de mulheres negras, sua mãe Luzia (nome fictício) é uma das mais antigas habitantes vivas de sua querência, é descendente de escravas, criou-se trabalhando como doméstica nas estâncias da cercania. Matriarca de uma família de cinco filh(a)os, na qual Maria é a mais velha. Logo, a escala espaço-temporal das trajetórias desse enlace, alcança explicitamente, relações espaço-temporais de longa duração na geohistória da Campanha Gaúcha, como as relações escravistas do século XIX.

Por sua vez, Pacácio, de origens mestiças, é oriundo do universo da peonagem. Seu pai percorreu diversas paragens até torna-se peão em uma estância de grande relevância. Com seus parcos recursos adquiriu

17 Romance na Tafona. Interpretes: Luiz Carlos Borges e Grupo Horizonte. Compositores: MACHADO, A. C.; BORGES L. C. In.: Lp.10a Califórnia da Canção Nativa do RS. Porto Alegre: K-Tel, 1980.

18 Tafona ou Atafona: palavra que designa uma pequena fabriqueta, ou engenho de produção de farinha de mandioca nas propriedades rurais de camponeses do Rio Grande do Sul, mas que com os processos de industrialização dos produtos agrícolas perdeu espaço para os grandes engenhos das indústrias que hegemonizam a produção de farinha de mandioca, por isso tornaram-se taperas (locais abandonados) 
uma pequena propriedade no corredor aberto pelos estancieiros, onde a família passou a viver. Assim, Pacácio cresceu no rincão, junto com seus irmãos e tornou-se peão conforme suas heranças familiares. Ao unirem-se em matrimônio, Pacácio e Maria passaram a percorrer diversas localidades, Pacácio trabalhando como peão, Maria como cozinheira. Até Pacácio receber o convite para trabalhar na estância em que seu pai trabalhava (após o falecimento do mesmo) e receber de herança seis hectares de terra, oriundos da partilha com seus irmãos.

É nessa pequena propriedade que Pacácio, Maria e sua família residem. 0 casal teve dois filhos. Entretanto, eles precisaram sair do rincão, tanto para estudar quanto para trabalhar, um tornou-se um trabalhador urbano, o outro também é peão de estância, mas sua família reside no espaço urbano. Como afirma Maria: - é que é tudo a necessidade né, de trabalhar, aqui não tem muito. E aí para melhorar de vida, para trabalhar melhor, tinha que sair. Questão indicativa dos processos de desreterritorialização que levam ao abandono dos rincões. Fato que se relaciona com as imposições do regime territorial, o qual restringe as possibilidades de acesso ao trabalho, monopoliza a propriedade da terra e invisibiliza a necessidade de políticas públicas para os moradores dos rincões.

Todavia, na pequena propriedade, a família possui umas vaquinhas e ovelhas, no dizer de Pacácio. Além de cavalos, galinhas livres no pátio, porcos, horta e plantas de cercado (mandioca, batata, abóbora, feijão, etc.), que são cultivadas dentro de um cercado de taquara (bambu), para a proteção dos animais invasores. Essa produção contribui ao autossustento da família. Ainda, Maria desde sua trajetória se reivindica como uma mulher criola do rincão e camponesa. A acepção de criola vai ao encontro de suas origens negras e escravas, bem como ao remeter-se ao sentimento de ser nativa do espaço-tempo do rincão. Não obstante, sua visão de camponesa ganha sentido no espectro do viver no campo, na Campanha, que se manifesta também enquanto categoria da prática. Essa condição de camponesa da Campanha se realiza de múltiplas formas, no trabalho com a produção de alimentos; no trato dos animais e cultivo da horta e do cercado; bem como nas relações familiares e na ajuda mútua entre os vizinhos, quatro elementos norteadores do modo de vida camponês segundo a leitura de Shanin (2008), terra, trabalho, família e comunidade.

Por conseguinte, Maria desde uma postura solidária, possui uma espécie de bolichinho de Campanha ${ }^{19}$ em sua casa. Busca na cidade bebidas, cigarros e fumo, alimentos a ser vendidos para quem mora no rincão, por um preço considerado justo, tendo em vista as dificuldades de acesso ao urbano e a ausência de locais de comércio neste espaço. Também em sua postura solidária, Maria e Pacácio já acolheram famílias desabrigadas no galpão de sua propriedade. Ainda, Maria é costureira e lavadeira. Esta multiplicidade de práticas e saberes, faz parte de uma espécie de fabricação conforme o termo de De Certeau (2014 [1990]), que jogo com/contra, nas tenologias de poder, manifestando um uso e um consumo austucioso das relações em que os sujeitos estão inseridos, como uma criatividade dispersa (bricolagem), presente na r-existência dos subalternos.

Por seu turno, em sua memória o casal aciona como principal referência das transformações espaçostemporais vividas, o âmbito do lar, em especial a casa. Desse modo, as múltiplas formas de sobrevivência descritas, ganham sentido na expressão suor do trabalho para construir melhores condições de vida. Assim, a família se orgulha da casa em que vive - que outrora fora dividida com lata e que atualmente se ampliou com peças de alvenaria. Nesse contexto, o lar se coloca como a escala espaço-temporal fundamental ao exercício da vida para esses sujeitos, o que vai ao encontro de Sack (2011 [1986]), quando este trabalha a pequena escala familiar do lar, como indicativa da presença da territorialidade humana em todos os lugares da vida moderna. É neste espaço, que brotam as relações de apropriação enquanto, afetividade e amor pelo seu chão.

Cabe destacar, ainda, que a trajetória desta família, encerra em si múltiplas matrizes dos processos de subalternização na Campanha Gaúcha, da condição escrava, à de peões e camponese(a)s. Assim, as forças, materiais e simbólicas, a partir do papel exercido pelas mulheres, como a matriarca Luzia e sua filha Maria, a qual em sua multiplicidade de saberes e práticas, conduz as diretrizes familiares nas quais Pacácio é parte integrante. Portanto, há um ponto de inflexão no qual a matriarcalidade negra e camponesa joga contra os efeitos da colonialidade, patriarcal e machista, branca e terratenente no contexto da Campanha Gaúcha.

Desta forma, a multiplicidade dos saberes, fazeres

19 Bolichos de Campanha: são locais de comércio e lazer situados à beira das estradas próximos ou nos rincões, onde se comercializam produtos variados, alimentos, bebidas, fumo e cigarros. Também é um espaço de lazer, onde se realizam jogos como o Truco, o Jogo de Osso (de origens espanhola), o Jogo de Bocha; festejos populares como Bailes, Rodeios e Carreiras (corrida de cavalos), naqueles de maior estrutura. Na contemporaneidade os bolichos já não se fazem mais tão presentes nas localidades, seja em função do despovoamento, assim como da maior concentração do comércio e do lazer nos espaços urbanos. 
e dos significados incorporados na trajetória de Maria e Pacácio, reforçam a natureza dos processos de desreterritorialização vividos pelos sujeitos nos rincões da Campanha Gaúcha, em questão, nos quais os sujeitos subalternizados passam a se apropriar das margens espaciais que os rincões representam, no sentido de servir às suas necessidades e possibilidades (LEFEBVRE 2013[1974]). Também destaca-se que os fazeres e saberes, em especial no caso da trajetória de Maria, possuem uma ambivalência, eles se voltam para fora, na alteridade, porque Maria manifesta o desejo de ajudar as pessoas e ao mesmo tempo se voltam para dentro do seio familiar em busca de melhores condições de vida. Portanto, este saber-fazer está inscrito em uma solidariedade, advinda de um modo de sentir e pensar ${ }^{20}$ no outro, própria de sua ancestralidade e relação com o chão em que se vive. Isso corrobora que nos rincões da Campanha Gaúcha analisados, o territitório em construção pode ser intepretado como "o chão mais a identidade" (SANTOS, 1999 p.8), tecido na r-existência cotidiana.

\section{Considerações finais}

Ao sugerir a noção de trajetória espaço-temporal, como uma ponte conceitual que permite adentrar com maior acuidade nas relações territoriais, este artigo apoiou-se nas experiências encontradas em alguns rincões da Campanha Gaúcha, compreendendo-os como espaço-tempos formados por múltiplos sujeitos subalternizados, cujas trajetórias se encontram, se fazem e se refazem nestes espaço-tempos. Assim, esses rincões podem ser interpretados, para além da condição de fundos territoriais a ser dominados e controlados pelos agentes hegemônicos-dominantes. Pois, o enlace das trajetórias espaço-temporais que os constituem, possibilitam identificar os processos de des-reterritorialização subalterna, que produzem nos respectivos rincões, territórios em construção sob a perspectiva de seus sujeitos subalternos, densos de relações materiais e simbólicas.

Nestes rincões, o exercício da vida, o amor ao ambiente e seus múltiplos sujeitos, se estende às relações de solidariedade e reciprocidade humanas, ainda que as situações de precarização, sejam marcas da subalternidade imposta a esses territórios. Todavia, revisitar a Campanha Gaúcha sob este prisma, não é

20 Escobar (2014), desde as experiências de vida e luta de indígenas, afrodescendentes e campesinos da América Latina aborda o sentipensar com os territórios, uma concepção que implica em pensar desde o coração e a mente, constituindo uma co-razão enquanto arte de viver ou conviver na diversidade da terra e dos territórios. Esse termo foi popularizado através dos trabalhos do sociólogo colombiano Orlando Fals Borda (1925-2008), junto as comunidades ribeirinhas da Centro-América. apenas um exercício de método que deseja refletir sobre as mediações na abordagem entre a categoria espaçotempo e o conceito de território. Mas, é sobretudo, uma implicação com as vidas e a riqueza de suas experiências, a quais são constitutivas da diversidade territorial vigente na região, ainda que subjugadas na hegemonia e dominação do regime territorial aludido. 
Referências bibliográficas

AGAMBEN, G. (2002). Homo Sacer: o poder soberano e a vida nua I. Belo Horizonte: Editora UFMG.

ARENDT, H. (1985 [1970]). Da violência. Brasília: Editora UNB.

BOURDIEU. P. (1996). A ilusão biográfica. In: BOURDIEU, P. Razões práticas: sobre a teoria da ação. Campinas: Papirus, p.74-82.

(2005). O poder simbólico. Rio de Janeiro: Bertrand Brasil.

(2009). Campo do poder, campo intelectual e habitus de classe. In: MICELI, S. (Coord.). Pierre Bourdieu: a economia das trocas simbólicas. São Paulo: Perspectiva, 2009, p.183-202.

BRAUDEL, F. (1990 [1958]). História e Ciências Sociais. 6a Ed. Lisboa: Editorial Presença.

BURAWOY, M. (2014). Marxismo sociológico: quatro décadas, quatro grandes transformações e uma tradição crítica. São Paulo: Alameda.

CASTORIADIS, C. (1982). A instituição imaginária da sociedade. 5a Ed. Rio de Janeiro: Paz e Terra.

CASTRO-GÓMEZ, S.; GROSFOGUEL, R. (2007). Prólogo. Giro decolonial, teoría crítica y pensamiento heterárquico. In: CASTRO-GÓMEZ, S.; GROSFOGUEL, R. (org.). El giro decolonial: reflexiones para una diversidad epistémica mas allá del capitalismo global. Bogotá: lesco Pensar; Siglo del Hombre Editores, p.9-23.

CHELOTTI, M. C. (2009). A estância metamorfoseou-se: (re)configurações territoriais e expressões da reterritorialização camponesa na Campanha Gaúcha (1990-2007). 288 f. Tese (Doutorado em Geografia) - Universidade Federal de Uberlândia, Uberlândia.

CRESSWELL, T. (2006). On the move: mobility in the modern western world. New York; London: Routledge Taylor; Francis Group.

DE CERTEAU, M. (2014 [1990]). A invenção do cotidiano: artes de fazer. 20a Ed. Petrópolis: Vozes.

DELEUZE, G.; GUATTARI, F. (1992). O que é a filosofia. Rio de Janeiro: Editora 34. (2000 [1980]). Mil Platôs. Capitalismo e Esquizofrenia (Vol.1). Rio de Janeiro: Editora 34.

DI MÉO, G.; BULÉON, P. (2005). L'espace social: une lecture géographique des sociétés. Paris: Armand Colin.

ESCOBAR, A. (2014). Sentipensar con la tierra. Nuevas lecturas sobre desarrollo, territorio y diferencia. Medellín: Ed.UNAULA.

FOUCAULT, M. (1995 [1982]). O sujeito e o poder. In: DREYFUS, H. L.; RABINOW, P. Michel Foucault: uma trajetória filosófica para além do estruturalismo e da hermenêutica. Rio de Janeiro: Forense Universitária, p.231-249.

(1999 [1976]). História da Sexualidade l: a vontade de saber. 13a Ed. Rio de Janeiro: Edições Graal.

(2005 [1976a]). Em defesa da sociedade. São Paulo: Martins Fontes.

(2008 [1978]) Segurança, Território, População. São Paulo: Martins Fontes,

(2014[1975]) Vigiar e Punir: o nascimento da prisão. 42a Ed. Petrópolis: Vozes.

FREIRE, P. (2012 [1968]). Pedagogia do Oprimido. 50a Ed. Rio de Janeiro: Saraiva.

GRAMSCI, A. (2014 [1934]). Caderno 25 - Às margens da história (História dos grupos sociais subalternos). In: GRAMSCI,

A. Cadernos do Cárcere. O Risorgimento. Notas sobre a história da Itália (Vol.5). 3a Ed. Rio de Janeiro: Civilização Brasileira, p.131-145.

HAESBAERT, R. (1988). RS: latifúndio e identidade regional. Porto Alegre: Mercado Aberto.

(2004). O mito da desterritorialização: do "fim dos territórios" à multiterritorialidade. Rio de Janeiro: Bertrand

Brasil.

(2009). Dilema de conceitos: espaço-território e contenção territorial. In: SAQUET, M. A.; SPÓSITO, E. S. (Org.).

Território e Territorialidades: teorias, processos e conflitos. São Paulo: Expressão Popular, p.95-120.

(2010). Regional-Global: dilemas da região e da regionalização na geografia contemporânea. Rio de Janeiro:

Bertrand Brasil.

(2014). Viver no Limite: território e multi/transterritorialidade em tempos de in-segurança e contenção. Rio de Janeiro: Bertrand Brasil.

HARVEY, D. (2012 [2006]). O espaço como palavra-chave. GEOgraphia, Niterói, n.28, p.9-39.

HEIDRICH, A. L. (2000). Além do latifúndio: geografia do interesse econômico gaúcho. Porto Alegre: Editora UFGRS.

LEFEBVRE, H. (2013 [1974]). La producción del espacio. 1a Ed. Madri: Capitán Swuing.

MARX, K. (2013[1867]). O Capital: crítica da economia política. Livro I. 1a Ed. São Paulo: Boitempo.

MASSEY, D. (2008). Pelo Espaço: uma nova política da espacialidade. Rio de Janeiro: Bertrand Brasil.

MIGNOLO, W. (2003). Histórias Locais/Projetos Globais: colonialidade, saberes subalternos e pensamento liminar. Belo 
Horizonte: Editora UFMG.

(2005). Espacios geográficos y localizaciones epistemologicas: la ratio entre la localización geográfica y la subalternización de conocimientos. GEOgraphia, Niterói, n.13, p.7-28.

MORAES, A. C. R. (2000). Bases da formação territorial no Brasil. São Paulo: Hucitec.

. (2013). Território na geografia de Milton Santos. São Paulo: Annablume.

OSÓRIO, H. (2016). Pastores e Lavradores do Rio Grande do Sul, séculos XVIII e XIX. In: WAQUIL, P. D. et al. Pecuária familiar no Rio Grande do Sul: história, diversidade social e dinâmicas de desenvolvimento. Porto Alegre: Editora UFRGS, p.15-40.

PORTO-GONÇALVES, C. W. (2002). Da geografia às geo-grafias: um mundo em busca de novas territorialidades. In: CECEÑA, A. E.; SADER, E. (org.). La Guerra Infinita: hegemonía y terror mundial. Buenos Aires: CLACSO, p. 217-256.

(2003). A geograficidade do social: uma contribuição para o debate metodológico sobre estudos de conflito

e movimentos sociais na América Latina. Beunos Aires: Clacso, 2003.p.1-11.

(2006). A reinvenção dos territórios. A experiência latino-americana e caribenha. In: CECEÑA, A. E. (org.) Los desafíos de las emancipaciones en un contexto militarizado. Buenos Aires: CLACSO, p.151-197.

(2008). De saberes e de territórios. Diversidade e emancipação na experiência latino-americana. In: CECEÑA,

A. E. (org.). De los saberes de la emancipación y de la dominación. Buenos Aires: Clacso, p. 37-52.

POULANTZAS, N. (1980). O Estado, o poder e o socialismo. Rio de Janeiro: Edições Graal.

QUIJANO, A. (2007). Colonialidad del poder y clasificación social. In: CASTRO-GÓMEZ, S.; GROSFOGUEL, R. (org.) El giro decolonial: reflexiones para una diversidad epistémica mas allá del capitalismo global. Bogotá: lesco Pensar; Siglo del Hombre Editores, p. 93-126.

(2014) "Bien Vivir". Entre el "desarrollo" y la Des/Colonialidad del Poder. In: QUIJANO, A. Cuestiones y horizontes: de la dependencia histórico-estructural a la colonialidad/descolonialidad del poder. Buenos Aires: CLACSO, p. 847-859.

RAFFESTIN, C. (1993[1980]). Por uma Geografia do Poder. São Paulo: Ática.

(1988). Repères pour une théorie de la territorialité humaine. In: DUPUY, G. (Dir.) Réseaux Territoriaux. Caen: Paradigme, p.263-279.

SACK, R. (2011[1986]). O significado de territorialidade. In: Dias, L.; Ferrari, M. (Org.). Territorialidades Humanas e Redes Sociais. Florianópolis: Insular, p.5-27.

SANTOS, M. (2002 [1996]). A Natureza do Espaço: Técnica e Tempo, Razão e Emoção. 4a Ed. São Paulo: Edusp. (1999). O dinheiro e o território. GEOgraphia. Niterói, n.1.p.7-13.

SANTOS, M.; SILVEIRA, M. L. (2001). O Brasil: território e sociedade no século XXI. Rio de Janeiro: Bertrand Brasil. SCOTT, J. (2013 [1990]). A dominação e a arte da resistência. Discursos ocultos. Lisboa: Letra Livre.

SHANIN, T. (2008). Lições Camponesas. In: PAULINO, E. T.; FABRINI, J. E. (org.). Campesinato e territórios em disputa. São Paulo: Expressão Popular, p.23-47.

SOUZA, M. L. (1995). O território: sobre espaço e poder, autonomia e desenvolvimento. In: CASTRO, I. E.; GOMES, P. C. C.; CORRÊA. R. L. (Org.). Geografia conceitos e temas. Rio de Janeiro: Bertrand Brasil, p.77-116.

(2009). Território da divergência (e da confusão): em torno das imprecisas fronteiras de um conceito fundamental. In: SAQUET, M. A.; SPÓSITO, E. S. (Org.). Território e Territorialidades: teorias, processos e conflitos. São Paulo: Expressão Popular, p.57-71.

. (2013). Os conceitos fundamentais da pesquisa sócio-espacial. Rio de Janeiro: Bertrand Brasil.

WEBER, M. (1999 [1920]). Economia e Sociedade: fundamentos da sociologia compreensiva (Vol. 2). Brasília, DF: Editora UNB; São Paulo: Imprensa Oficial do Estado de São Paulo.

\section{Documentos sonoros}

O MANGRULHO. Interpretes: Jorge André e Grupo Uruches. Compositores: ALVES, K.; VASCONCELLOS, M. A. In.: Lp.10a Califórnia da Canção Nativa do RS. Porto Alegre: K-Tel, 1980.

ROMANCE NA TAFONA. Interpretes: Luiz Carlos Borges e Grupo Horizonte. Compositores: MACHADO, A. C.; BORGES L. C. In.: Lp.10a Califórnia da Canção Nativa do RS. Porto Alegre: K-Tel, 1980. 